\title{
Reparación de las cubiertas y de la torre de la capilla de La Cadellada, Oviedo
}

\author{
Miguel Crespo Vázquez \\ Arquitecto \\ Daniel Simarro González \\ Arquitecto
}

RESUMEN

La Capilla de La Cadellada está ubicada junto al Hospital Universitario Central de Asturias y perteneció al antiguo Hospital Provincial Psiquiátrico de "La Cadellada". Fue proyectada en estilo neorrománico en 1940 por el arquitecto Manuel Bobes y finalizada su construcción en 1944. Está incluida en las "Fichas de Catálogo de Bienes Protegidos" del PGOU de Oviedo con protección Integral Singular. La Capilla se construyó usando mampostería de piedra en muros y contrafuertes. Los elementos singulares se resolvieron con ladrillo o rasilla. Destacan la solución estructural mixta de la cubierta principal y las bóvedas tabicadas de la sacristía. Para definir la intervención que describe este artículo, realizamos un análisis patológico para identificar las lesiones y determinar sus causas. Fruto del conocimiento del edificio y de su estado de conservación, planteamos una intervención respetuosa consistente en la consolidación de la estructura soporte y la resolución de las filtraciones de agua de lluvia.

PALABRAS CLAVE

Capilla, Cadellada, reparación, estructura, filtraciones.

\section{Cadellada Chapel, Oviedo, Spain. Repair of the roofs and the tower}

ABSTRACT

Cadellada Chapel is located next to the Central University Hospital of Asturias and belonged to the old Provincial Psychiatric Hospital ("La Cadellada"). It was designed in neo-Romanesque style in 1940 by the architect Manuel Bobes and its construction was completed in 1944. It is included in the protected properties' technical data sheets of the General Urban Development Plan (PGOU) of Oviedo. The Chapel was built using stone masonry in walls and buttresses. The singular elements were resolved with brick or tile board. The mixed structural solution of the main roof and the partitioned vaults stand out. To define the works described in this article, we carried out a pathological analysis to identify the lesions and determine their causes. As a result of our knowledge of the building and its state of conservation, we proposed a respectful intervention consisting of the consolidation of the supporting structure and the resolution of rainwater filtrations.

\section{KEYWORDS}

Chapel, Cadellada, repair, structure, leaks 


\subsection{Situación del edificio. Autor}

La “Capilla de La Cadellada” está ubicada en la parcela del Hospital Universitario Central de Asturias (en adelante HUCA), dentro de la trama urbana localizada al nordeste del casco urbano de Oviedo y delimitada por los barrios de Teatinos, La Corredoria y Prado de la Vega. La ubicación de la parcela es estratégica dentro del área central metropolitana.

Este edificio perteneció al antiguo Hospital Provincial Psiquiátrico de "La Cadellada", un equipamiento proyectado en 1926 por Manuel Bobes Díaz (1879-1947), arquitecto de la Diputación Provincial. El Hospital Provincial estaba alejado de la ciudad histórica, en un entorno rural que progresivamente pasó a convertirse en un área periférica en continuidad espacial con la ciudad y el área central.

\subsection{Antecedentes Históricos. Marco socio- político}

El Hospital Psiquiátrico de "La Cadellada”, de estilo neorrománico simplificado, fue un complejo hospitalario de clara inspiración centroeuropea, concebido como un modelo arquitectónico revolucionario dentro del ámbito sanitario. Su organización giraba en torno a la terapia ocupacional y a la distribución funcional en múltiples pabellones y espacios ajardinados. Uno de estos pabellones, el número 4, era el denominado "Pabellón para Capilla".

Fue severamente dañado durante la Guerra Civil Española en febrero de 1937 y posteriormente, en 1940 el "arquitecto Manuel Bobes Díaz realizó el proyecto específico definitivo para el Pabellón para Capilla” cuya construcción finalizó en 1944.

En el año 1963, el artista ovetense Paulino Vicente realizó una pintura mural interior ocupando todo el muro testero de la Capilla con figuras de tamaño mayor que el natural, adecuándose perfectamente al espacio arquitectónico. El mural, que representa la Última Cena, fue pintado al temple sobre una base de estuco de yeso.

La Capilla permaneció en funcionamiento hasta su trasferencia a la Consejería de Salud del Principado de Asturias y posteriormente fue desacralizada en junio de 2005 con el inicio de las obras del HUCA.
En el edificio se distinguen perfectamente tres volumetrías generadas en planta:

- El cuerpo de entrada está formado por la torre-campanario que alcanza 27,40m. en su punto más alto. Al haberse construido recientemente una plaza de acceso, se puede decir que es el volumen que mejor representa las proporciones proyectadas por Manuel Bobes.

- La nave longitudinal, constituye el cuerpo central de la Capilla y define un ritmo de cinco contrafuertes y arcos fajones con unas importantes vidrieras situadas entre los contrafuertes.

- En el testero sur aparece la sacristía como un volumen diferenciado. Tanto la sacristía como la nave principal resuelven las cubiertas a dos aguas.

Y tres plantas:

- La planta sótano se adapta a la topografía natural y tenía uso destinado como almacén y cuartos de instalaciones. Está permanentemente ventilada gracias a los óculos laterales entre arcos fajones integrados en el zócalo de mortero.

- La planta principal es una nave de directriz longitudinal de $19,30 \mathrm{~m}$. de largo por 8,10 m. de ancho, construida con muros perimetrales de carga entre 60 y $75 \mathrm{~cm}$. de espesor. Una serie de cinco arcos fajones separados entre sí 4,90 m. definen el ritmo, que se apoyan en los contrafuertes de fábrica de ladrillo y revestidos por una gruesa capa de mortero de cal de $5 \mathrm{~cm}$. de espesor. El último tramo se encuentra elevado $48 \mathrm{~cm}$, generando el altar y se conecta con la "sacristía”. Entre los arcos fajones existen vidrieras de 1,45 x 3,00 m. que bañan de luz la nave principal. El testero sur se remata con otras tres vidrieras que se integran en el interior de la Capilla formando parte del mural realizado por Paulino Vicente.

- Existe una planta intermedia destinada para el coro que se conecta con el campanario a través de una escalera tabicada sobre el nártex, donde la planta cuadrada se transforma en un octógono. Sobre esa puerta de acceso al campanario corona una vidriera en forma de rosetón de 1,75 m. de diámetro. 


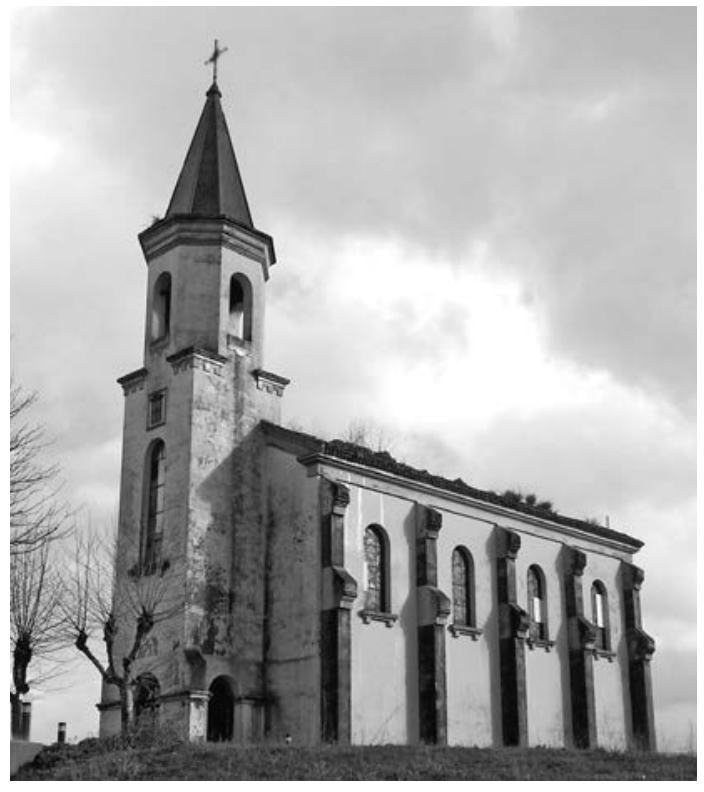

Fig. 1. Arquitecto: Manuel Bobes. Capilla de La Cadellada. Hospital Universitario Central de Asturias. Oviedo. Finalización: 1944. Foto tomada por los autores del artículo en 2015. Estado previo a la intervención.

La sacristía y la nave principal resuelven la planta de cubierta a dos aguas con teja cerámica curva roja, mientras que la pieza de entrada al campanario se remata con una pirámide octogonal de ladrillo terminada en mortero que simula el despiece de piezas rectangulares de tamaño considerable.

Es un edificio de un gran valor arquitectónico, al tratarse de un sistema constructivo desaparecido, que pertenece a la historia de la construcción y que hoy en día sería complejo reproducir. En consecuencia, es un edificio que se debe respetar y conservar tanto por su valor histórico-artístico como por estar incluido en las "Fichas de Catálogo de Bienes Protegidos" del Plan General de Ordenación Urbano del Ayuntamiento de Oviedo (2005) y por tener un grado de Protección Integral Singular (T).

\section{Descripción del edificio}

A partir del año 2005 se han llevado a cabo diferentes actuaciones en la parcela del antiguo complejo psiquiátrico de La Cadellada motivadas por la obra del nuevo HUCA. Principalmente con la demolición de edificios del antiguo complejo psiquiátrico, hemos obtenido información de primera mano que ayuda a entender la concepción constructiva de la Capilla de La Cadellada, tanto desde el punto de vista estructural como constructivo. La ejecución de las obras descritas en este artículo, acabaron de aportar la luz necesaria sobre estos asuntos para conocer mejor el edificio.

\subsection{Descripción general de los sistemas estructurales del edificio}

Todas las cargas de la cubierta, tanto los pesos propios, como las cargas de uso, nieve, etc. se transmiten a través de las celosías a los arcos fajones y de estos a los contrafuertes y finalmente a la cimentación. De esta manera la bóveda tabicada no soporta ninguna carga salvo su peso propio.

Para entender el funcionamiento estructural del edificio seguimos los pasos del proceso de ejecución de la obra. Sabemos que el edificio se apoya en el terreno con cimentación corrida de la que arrancan tanto los muros perimetrales de carga, de entre 65 y $70 \mathrm{~cm}$. de espesor, como los contrafuertes. Aproximadamente a mitad de luz entre los muros laterales paralelos, fue construida una línea de zapatas aisladas con sus respectivos pilares, estos de una planta de altura. Apoyadas en los pilares y en los contrafuertes se dispusieron vigas de canto sobre las que descansa el forjado de la nave principal. Esto quiere decir que la nave está sobreelevada dejando una cámara o planta inferior. El forjado estructural se apoya tanto en los muros de carga perimetrales como en las vigas de canto, las cuales tienen su luz partida por los pilares anteriormente mencionados.

Prosigue en vertical la construcción de los muros y contrafuertes hasta el nivel de arranque de los arcos. En la primera crujía de la Capilla y a media altura del espacio vertical de la nave, construyeron un forjado intermedio apoyado en su perímetro en los muros de carga y en una viga de canto en dirección perpendicular al eje principal de la Capilla. El siguiente paso fue construir, entre ejes de muros, los arcos fajones que salvan una luz de 8,7 m. sin apoyos intermedios. Posteriormente recrecieron los muros sobre el arranque de los arcos hasta el nivel de cornisa y se instaló una celosía metálica que se apoya en distintos puntos del trasdós del arco fajón y también, puntual y lateralmente, en los muros recrecidos. Esto genera un sistema estructural mixto ingenioso que permite pasar de la sección 


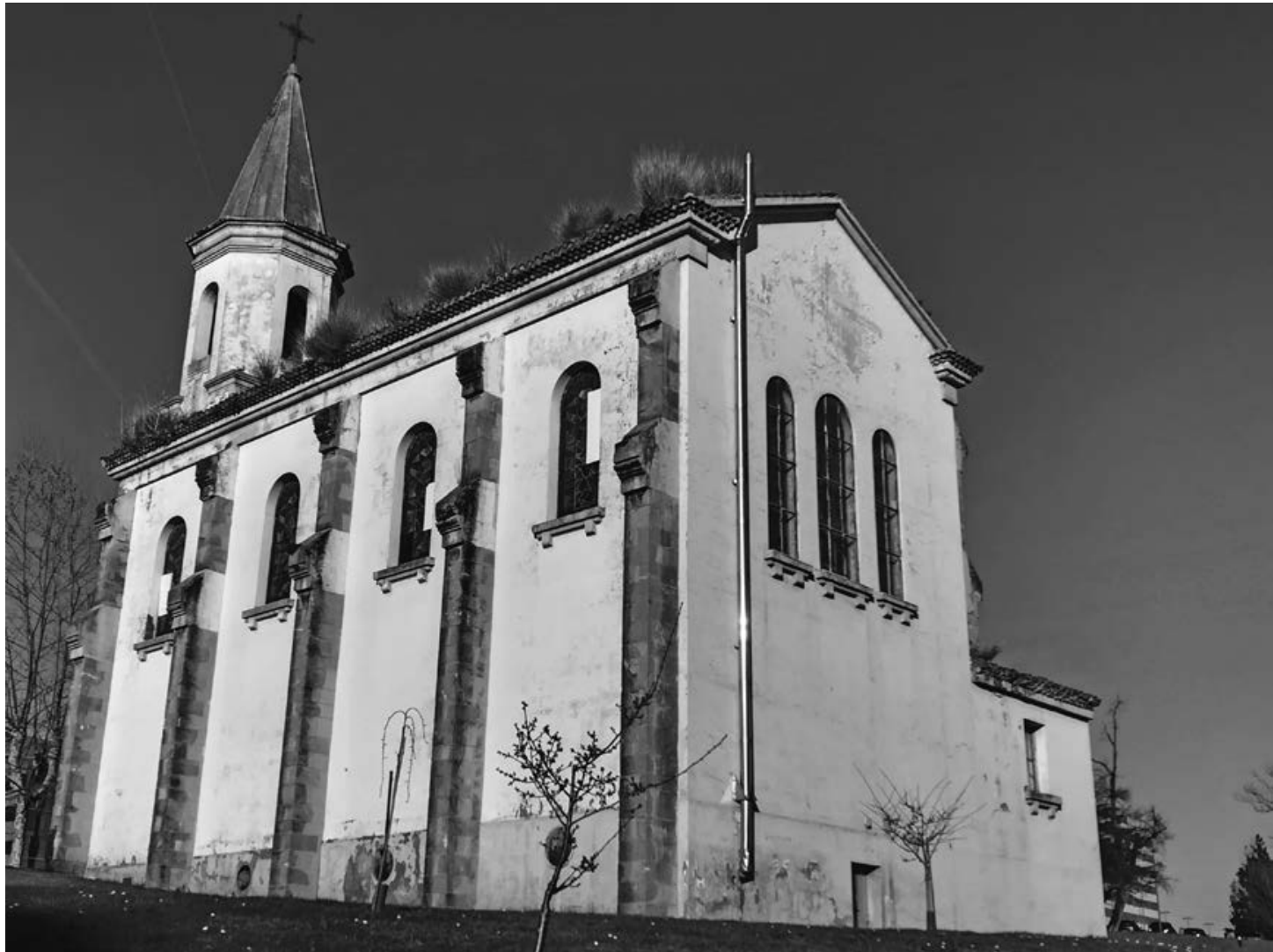

Fig. 2. Arquitecto: Manuel Bobes. Capilla de La Cadellada. Hospital Universitario Central de Asturias. Oviedo. Finalización: 1944. Foto tomada por los autores del artículo en 2015. Estado previo a la intervención.

curva a la sección "a dos aguas". El arco de ladrillo se podría asimilar estructuralmente al cordón inferior de la celosía metálica.

A continuación, se ejecutó la bóveda tabicada pasante por encima de los arcos fajones apoyada en los muros laterales de tal manera que empotra los nudos inferiores de la celosía, quedando totalmente ocultos por la bóveda, cuyo espesor aproximado es de $13 \mathrm{~cm}$. En la siguiente fase se dispusieron ocho correas metálicas sobre los cordones superiores de las celosías, salvando una luz entre estas de $4,9 \mathrm{~m}$.

Se prosiguió con el tablero de cubierta a dos aguas sirviéndose de las correas como base de apoyo. Este estaba compuesto por dos tortas de rasilla similar a la utilizada en la bóveda. A continuación, se ejecutaron pequeños petos sobre los faldones y en la dirección de máxima pendiente, que arrancaban en la cumbrera con una altura nula y que iban ganando elevación para alcanzar su mayor cota sobre el muro lateral de la Capilla. El espacio entre muretes se rellenó con escoria de mina. El proceso finalizó con el acabado de cubierta de teja árabe.

\subsection{Descripción general de los sistemas constructivos del edificio}

Para explicar la Capilla desde el punto de vista constructivo hemos realizado varias catas. Para conocer determinadas partes inaccesibles del edificio nos hemos servido de fotografías de calas hechas en uno de los edificios del complejo psiquiátrico, ejecutado en época similar y con los mismos sistemas constructivos.

Para entender el funcionamiento constructivo del edificio seguimos el mismo orden que en el punto anterior 2.1, partiendo de la cimentación, la cual se ejecutó en origen en piedra con un espesor mayor que el del muro y el de los contrafuertes, para repartir mejor las cargas al terreno.

En la información del proyecto original, a la que hemos tenido acceso, se describen muros de fábrica mixta de piedra y ladrillo. Sin embargo, las calas realizadas en varias zonas, muestran muros de piedra en todo su espesor. El ladrillo se utilizó sólo en puntos singulares en los que se requería de una base de piezas pequeñas para realizar formas concretas (arcos, jambas, molduras, etc.). 
La piedra está revestida por el interior con revoco de cal y pintura; y por el exterior, con mortero rico en arena y pintura. Todo ello genera un espesor de casi $70 \mathrm{~cm}$.

Las vigas y pilares de la planta inferior se construyeron de hormigón armado revestido con revoco. No se sabe si para el armado se utilizaron redondos de acero de la época o más bien, perfiles de acero "doble T", o similares, con un recubrimiento generoso de hormigón y un posterior acabado con enlucido pintado. Entendemos que quizá fue este último el sistema utilizado al haber encontrado siempre estructuras metálicas en los edificios del complejo y nunca redondos de acero embutidos en hormigón. Probablemente, los operarios de la época sabían que el acero estructural sufriría en este sótano húmedo y por eso lo protegieron con hormigón.

El forjado de la nave se construyó a base de viguetas de acero "doble T" de unos $18 \mathrm{~cm}$. de alto, un intereje aproximado de $70 \mathrm{~cm}$. y bovedilla cerámica de gran formato. Sobre este sistema se vertió una capa de compresión armada y como acabado se dispuso un pavimento de terrazo 40x40 de grano medio, en damero.

Los contrafuertes se realizaron recreciendo los muros con piedra aparejada con el mismo muro, unos $80 \mathrm{~cm}$. hacia el exterior y revistiéndola con mortero a base de la misma piedra triturada. Hacia el interior se utilizó ladrillo macizo formando una mocheta de $25 \mathrm{~cm}$. revestida con mortero de cal.

Partiendo de un plano horizontal de arranque, ejecutado con ladrillo macizo, se construyeron los arcos fajones de $50 \mathrm{~cm}$. de canto, con el mismo tipo de ladrillo, aparejado, salvando una luz de $8,7 \mathrm{~m}$. y revestido con rasilla como base de las molduras. Las calas que aportaron esta información las realizamos en la cara inferior y lateral del arco. Sin embargo, no fue posible penetrar hasta el alma o interior del arco para verificar el tipo de material utilizado en toda su sección.

La celosía metálica se apoya en el arco fajón sirviéndose de este como cordón inferior. El reparto de cargas al fajón se transmite en 7 puntos. Está formada por perfiles en L, de mayor sección en el cordón superior que en las diagonales interiores. En estas se ha detectado un recorte en el ala que reduce la sección útil. Parece ser que este tipo de barras fueron reaprovechadas de alambradas de la guerra. El recorte se usaba para fijar a varias alturas la espiral de alambre de espino. Las uniones se realizaron roblonadas a chapones metálicos de transición de esfuerzos. Las correas son perfiles "doble T" de unos $12-18 \mathrm{~cm}$. que salvan luces de 4,9 m. y presentan corrosión avanzada.

La bóveda se debe respetar y conservar, al estar ejecutada con un sistema que pertenece ya a la historia de la construcción y prácticamente en desuso hoy en día. Se ejecutó arrancando de una base regular de ladrillo macizo en el muro de piedra. Está compuesta por tres roscas de rasilla fina de 2,5 cm. de espesor aparejadas en las dos direcciones y tomada, la primera rosca, con mortero de yeso. El conjunto tiene un espesor aproximado de $13 \mathrm{~cm}$., y describe una geometría semicircular salvando una luz de $8,4 \mathrm{~m}$. Se trata de un elemento constructivo de gran valor histórico, que aporta singularidad al edificio.

La cubierta está ejecutada con un tablero de dos capas de rasilla fina aparejadas. El espesor total es de 6-7 cm. El tablero se apoya en las correas metálicas formando una cubierta a dos aguas. Como se explicó en el apartado anterior 2.1, sobre el tablero se construyeron unos pequeños petos de ladrillo rellenados con escoria de mina. Esto permite modificar la pendiente de la cubierta haciéndola más suave $o$ tendida. Con esto sospechamos que se evitó la formación de "refreno" en la parte baja de la cubierta, en el encuentro con el alero de cornisa. Finalmente, la cubierta se terminó con teja árabe dispuesta a canal y cobija. El detalle de cornisa está formado por cuatro niveles de tejas que vuelan uno respecto al inferior.

La torre, de planta cuadrada y con muros perimetrales de mampostería de piedra, se concibió con un cambio de sección a la altura del forjado del campanario, pasando a forma octogonal. Para ello se realizaron cuatro pechinas en las esquinas del cuadrado. La escalera de acceso a la torre discurre perimetralmente al muro dejando un ojo interior. Está construida con bóvedas tabicadas en cada tramo entre descansillos, de probablemente dos roscas de rasilla cerámica apoyada en los muros de piedra. El forjado del campanario se ejecutó con bóvedas muy tendidas a base de roscas de rasilla cerámica apoyadas en el muro y en tres viguetas de acero "doble T" tipo IPN 120 de ala estrecha, de una serie antigua. El pináculo superior, muy esbelto y de base octogonal, está construido también con doble rasilla cerámica. Tiene dos crucetas de acero a dos alturas para arriostrar y hacer que el sistema trabaje solidariamente sin que las caras se puedan separar. 
Los muros de la sacristía están ejecutados con mampostería de piedra en todo su espesor. En la cubierta se utilizó un sistema constructivo a base de 4 bóvedas tabicadas de dos roscas de rasilla apoyadas en perfiles "doble T" de ala estrecha de $180 \mathrm{~cm}$. dispuestos a distinta cota, en forma triangular, para facilitar la formación de la cubierta a dos aguas. El detalle de encuentro con el muro, en el alero inferior se resolvió con un perfil de apoyo de madera que fue deteriorándose con el tiempo y debilitando la cubierta.

\section{Análisis del estado de conservación}

\subsection{Toma de datos. Ensayos y pruebas. Fichas de diagnóstico.}

Para conocer y comprender el funcionamiento estructural y constructivo de la "Capilla de La Cadellada" realizamos múltiples visitas al edificio en las que tomamos datos a través de fotografías, mediciones, inspecciones, testigos, etc.

\begin{tabular}{ll}
\hline \multicolumn{2}{c}{ Metodología DE TRABAJo: } \\
\hline $1 \begin{array}{l}\text { Análisis de la do- } \\
\text { cumentación }\end{array}$ & $\begin{array}{l}\text { Fondo del archivo histórico de } \\
\text { la Diputación Provincial. Análi- } \\
\text { sis del proyecto original y de las } \\
\text { reformas realizadas }\end{array}$ \\
\hline 2 Inspección Previa & $\begin{array}{l}\text { Recolección de datos del estado } \\
\text { del inmueble a través de foto- } \\
\text { grafías y de croquis }\end{array}$ \\
\hline 3 Toma de datos & $\begin{array}{l}\text { Ejecución de calas en bóveda de } \\
\text { cubierta, en muros de piedra, en } \\
\text { arcos de ladrillo y colocación de } \\
\text { testigos en torre }\end{array}$ \\
\hline 4 Inspección técnica & $\begin{array}{l}\text { Consulta a expertos del Labora- } \\
\text { tad de Getrofísica de la Facul- } \\
\text { dad de Oviedo de la Universi- }\end{array}$ \\
\hline $\begin{array}{l}\text { Diagnóstico e } \\
\text { Intervención }\end{array}$ & $\begin{array}{l}\text { Elaboración de las fichas de le- } \\
\text { siones del edificio para determi- } \\
\text { nar el diagnóstico del estado de } \\
\text { conservación }\end{array}$ \\
\hline
\end{tabular}

Sin embargo, han sido las distintas calas realizadas las que arrojaron a la luz datos fundamentales para comprender el edificio. Esta información nos permitió elaborar las fichas de lesiones del edificio y determinar sus causas (directas e indirectas), según la clasificación que se detalla a continuación:

\begin{tabular}{|c|c|c|c|}
\hline \multicolumn{4}{|c|}{ CUADRO DE LESIONES: } \\
\hline \multirow{3}{*}{$\begin{array}{l}\text { Lesiones } \\
\text { químicas }\end{array}$} & \multirow{3}{*}{ Directas } & Organismos & $\begin{array}{l}\text { Humedad, filtra- } \\
\text { ciones y falta de } \\
\text { aislamiento }\end{array}$ \\
\hline & & $\begin{array}{l}\text { Organismos } \\
\text { en faldones de } \\
\text { cubierta }\end{array}$ & $\begin{array}{l}\text { Falta de man- } \\
\text { tenimiento y de } \\
\text { limpieza de la } \\
\text { cubierta. Excesiva } \\
\text { humedad }\end{array}$ \\
\hline & & $\begin{array}{l}\text { Oxidación en } \\
\text { soporte de la } \\
\text { cobertura }\end{array}$ & $\begin{array}{l}\text { Filtraciones a } \\
\text { través de la cu- } \\
\text { bierta. Humedad } \\
\text { ambiental sin } \\
\text { ventilación }\end{array}$ \\
\hline \multirow{3}{*}{$\begin{array}{l}\text { Lesiones } \\
\text { físicas }\end{array}$} & \multirow{3}{*}{ Directas } & $\begin{array}{l}\text { Humedades de } \\
\text { filtración en la } \\
\text { cubierta prin- } \\
\text { cipal }\end{array}$ & $\begin{array}{l}\text { Entrada de agua } \\
\text { a través de la } \\
\text { cubierta y fisuras } \\
\text { de fachada }\end{array}$ \\
\hline & & $\begin{array}{l}\text { Humedades de } \\
\text { filtración en la } \\
\text { cubierta de la } \\
\text { sacristía }\end{array}$ & $\begin{array}{l}\text { Entrada de agua } \\
\text { a través de la } \\
\text { cubierta y fisuras } \\
\text { de fachada }\end{array}$ \\
\hline & & $\begin{array}{l}\text { Fisuras en coro- } \\
\text { nación de muro }\end{array}$ & $\begin{array}{l}\text { Movimientos de } \\
\text { materiales debi- } \\
\text { dos a cambios } \\
\text { térmicos. Falta de } \\
\text { aislamiento }\end{array}$ \\
\hline \multirow{3}{*}{$\begin{array}{l}\text { Lesiones } \\
\text { mecánicas }\end{array}$} & \multirow{3}{*}{$\begin{array}{l}\text { Directas e } \\
\text { indirectas }\end{array}$} & $\begin{array}{l}\text { Pérdida de so- } \\
\text { lape en material } \\
\text { de cobertura }\end{array}$ & $\begin{array}{l}\text { Falta de manteni- } \\
\text { miento y sistema } \\
\text { constructivo en } \\
\text { fallo. Genera } \\
\text { filtraciones }\end{array}$ \\
\hline & & $\begin{array}{l}\text { Fisuraciones en } \\
\text { arcos fajones }\end{array}$ & $\begin{array}{l}\text { Transmisión de } \\
\text { esfuerzos de } \\
\text { tracción de la } \\
\text { celosía metálica a } \\
\text { la clave del arco }\end{array}$ \\
\hline & & $\begin{array}{l}\text { Grietas y fisuras } \\
\text { en el campa- } \\
\text { nario }\end{array}$ & $\begin{array}{l}\text { Cambio de sec- } \\
\text { ción de cuadrado } \\
\text { a octógono, } \\
\text { huecos grandes, } \\
\text { empujes horizon- } \\
\text { tales }\end{array}$ \\
\hline
\end{tabular}



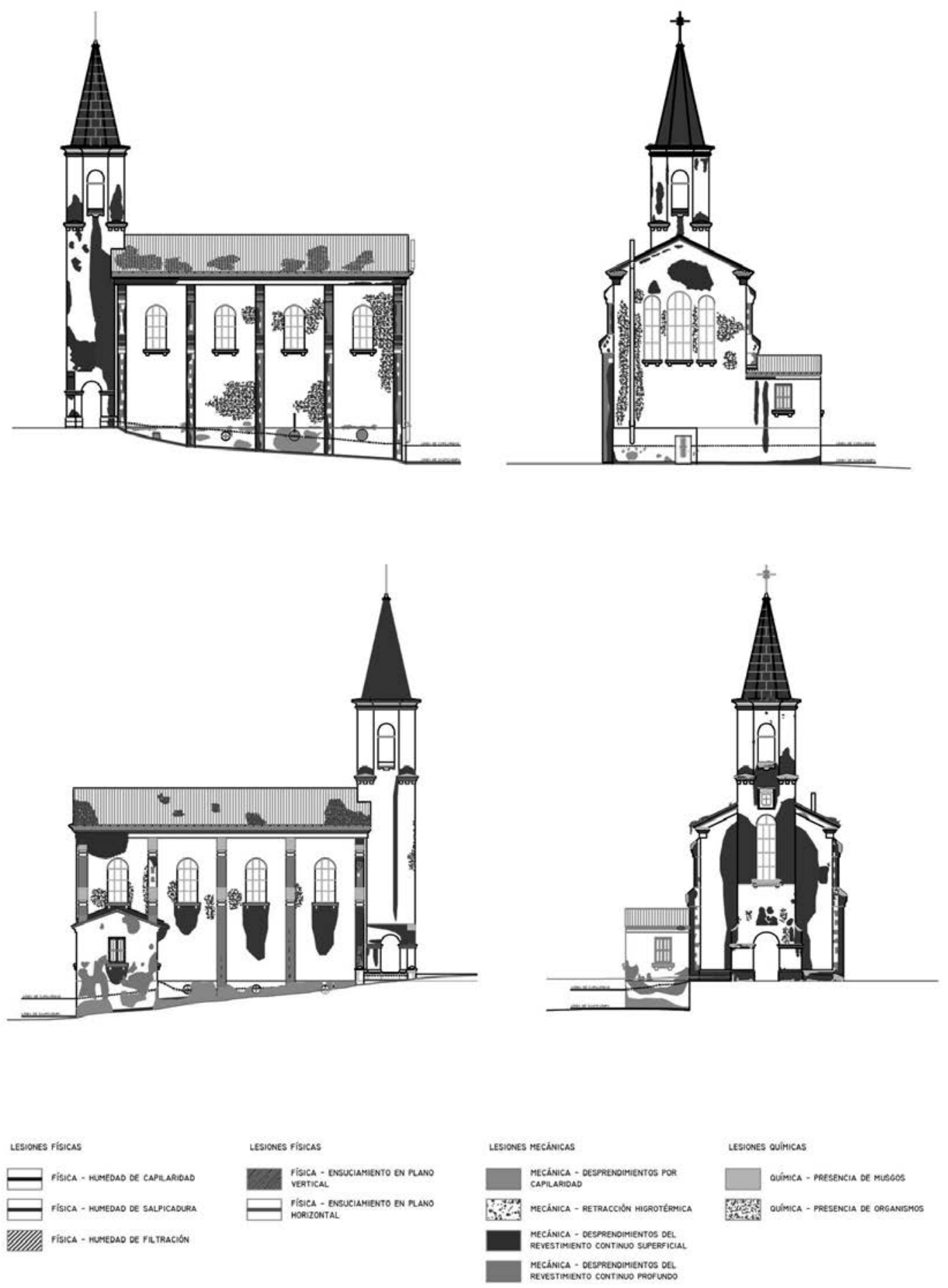

Fig. 3. Los autores del proyecto. Estudio patológico de la Capilla de La Cadellada. Planos de lesiones mecánicas, físicas y químicas. 2019. 
Resulta necesario identificar y clasificar tipológicamente las lesiones existentes en el edificio y los factores que las causaron. Para conocer el estado patológico es imprescindible determinar las causas (activas o pasivas) que originaron el proceso y que desembocaron en una o varias lesiones. De este modo se puede resolver el problema patológico en origen y evitar que aparezca de nuevo.

\subsection{Análisis patológico del edificio. Zonas de intervención.}

La justificación funcional de esta intervención para la conservación y la reparación de las cubiertas y de la torre está basada en el estado patológico en el que se encuentran. La edificación tiene lesiones físicas, químicas y mecánicas detectadas tanto en el sistema de cubiertas como en la torre del campanario, haciendo necesaria una intervención con el fin de repararlas y conservar la calidad de la edificación.

Hemos realizado un análisis patológico de la Capilla detectando aquellos problemas que le afectan en cualquiera de sus elementos constructivos. Para ello hemos realizado calas en el edificio y en otras construcciones pertenecientes al complejo sanitario; se ha trabajado en un análisis petrológico de la piedra de los contrafuertes; se han clasificado las lesiones, se han localizado y se han instalado fisurómetros durante la ejecución de la obra para analizar la evolución de las fisuras más destacadas. Se planteó una intervención exterior con la doble intención, por un lado, de consolidar y asegurar estructuralmente el edificio y, por otro lado, de reparar las cubiertas para eliminar las filtraciones al interior de agua de lluvia. Efectivamente cabría la posibilidad de realizar una reparación de mayor calado actuando sobre otras patologías, como las filtraciones de agua proveniente del terreno y también sobre los daños que estas han causado en el interior. Sin embargo, esto se tendrá que realizar en una intervención posterior a la descrita en este artículo.

\subsubsection{Sistema de cubiertas}

Por un lado, con relación al sistema de cubiertas de la nave principal y de la sacristía, las lesiones detectadas fueron las siguientes: a.- Material de cobertura: sistema discontinuo de teja curva:

- Pérdida de solape en el material de cobertura

- Erosiones mecánicas

- Desprendimientos de teja, especialmente en los aleros de tejaroz

- Erosiones físicas

- Aparición de organismos en la cubierta

- Heladicidad de la teja cerámica curva

b.- Lesiones detectadas en la base estructural de la cubierta:

- Flecha en los perfiles de acero

- Pandeo lateral de las correas de soporte del tablero de cubierta

- Corrosión en los perfiles de acero

- Pérdida de sección debido a la corrosión y a defectos de fabricación

- Fisuras en los arcos fajones

c.- Sistema de evacuación:

- Pérdida de solape en el material de cubrición

- Erosiones mecánicas de las tejas cerámicas curvas

- Erosiones físicas de las tejas cerámicas curvas

- Aparición de organismos en la cubierta

- Penetraciones

d.- Sistema higrotérmico:

- Ausencia de aislamiento

- Fisuras en la coronación de muros

- Movimientos térmicos

El mismo tipo de daños y lesiones señalados en la cubierta principal de la nave se detectaron en la sacristía, de tal manera que provocaban humedades de filtración por movimiento de tejas, desprendimientos en paramentos por falta de alero y corrosión de las estructuras metálicas. El detalle incorrecto del nervio lateral de apoyo de las bóvedas tabicadas propició la filtración directa de agua (con el movimiento de tejas), causando la pudrición de los materiales que conforman la envolvente de la sacristía. 

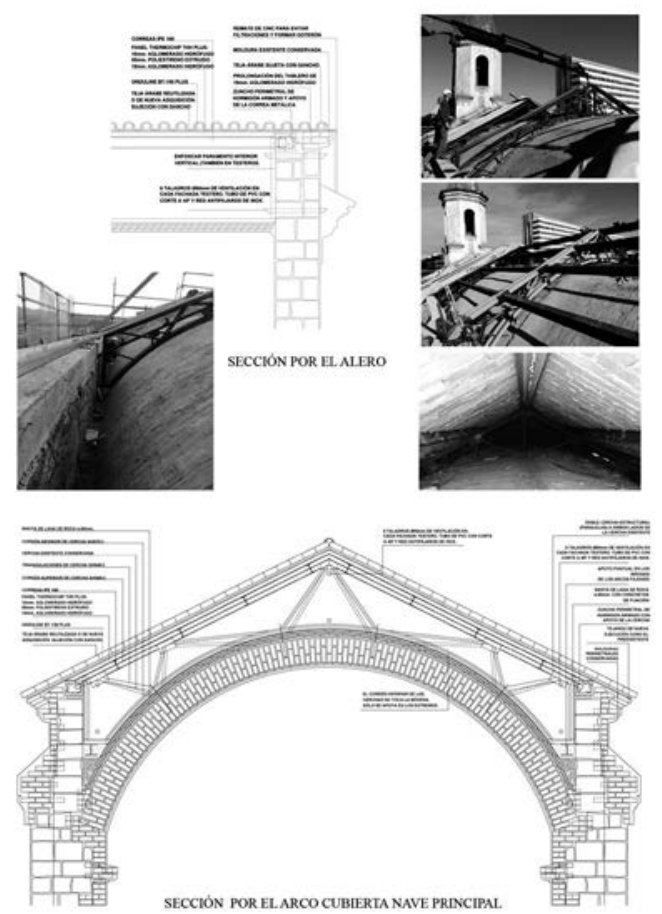

Fig. 4. Los autores del proyecto. Capilla de La Cadellada. Cubierta de la nave principal. Planos de la propuesta del refuerzo estructural. Detalles constructivos de la estructura. Fotografías de la ejecución de la obra. 2019 - 2020

\subsubsection{Torre del campanario}

Por otro lado, con relación a la torre del campanario de la Capilla, se han descubierto lesiones mecánicas que muestran su sintomatología a modo de grietas que han ido aumentando de espesor con el paso del tiempo.

En un primer análisis, parece que los muros de carga de la torre se estuvieran abriendo como efecto de las cargas que le transmite la cubierta (componente vertical y componente horizontal de la fuerza) y del debilitamiento de estos debido a los cuatro huecos de ventanal que hacen que tenga una importante pérdida de rigidez y de resistencia en sus cuatro caras.

El cambio de sección que experimenta la torre a la altura del forjado del campanario y de la parte baja de los huecos anteriormente mencionados, pasando de planta cuadrada a planta octogonal, debilita estructuralmente la torre. Además, es importante añadir el hecho de que se trata de una fábrica de mampostería en la cual podría existir falta de trabazón de sus elementos. El forjado de rasilla tabicada apoyada en perfilería metálica, que sirve de acceso a la campana, transmite esfuerzos rasantes a la fábrica a esa altura, produciendo la fisura

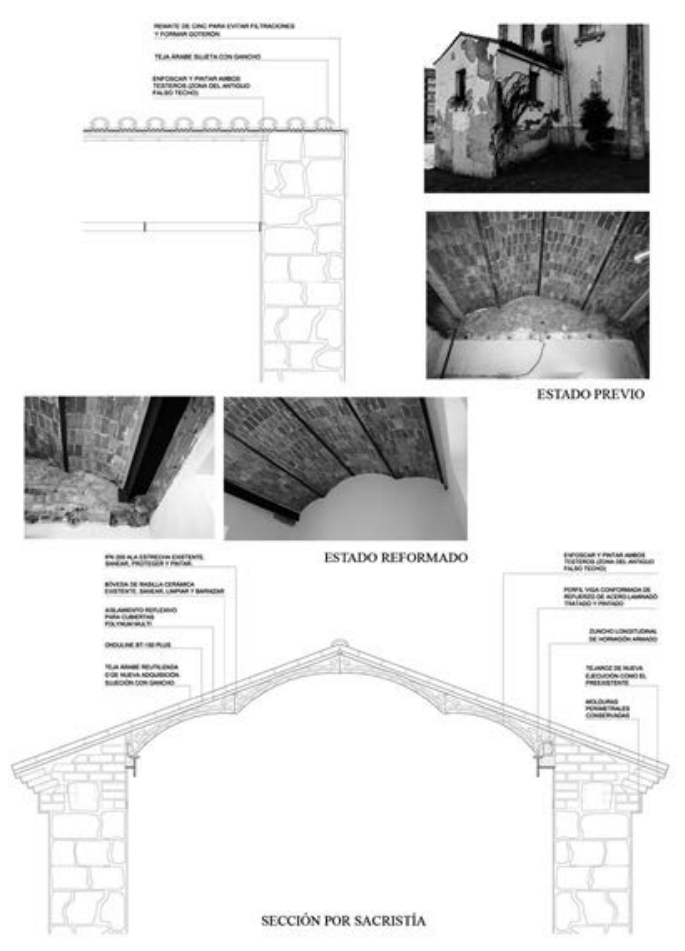

183

Fig. 5. Los autores del proyecto. Capilla de La Cadellada. Cubierta de la sacristía. Planos de la propuesta de reparación. Detalles constructivos de la estructura. Fotografías del estado previo y de la ejecución de la obra. 2019 - 2020.

perimetral continua. Aparecen por un lado las grietas verticales como consecuencia de unas tracciones en sentido perpendicular a las mismas, y por otro lado se nos muestra una fisura horizontal que rodea la torre, como consecuencia de un pandeo fuera del plano y del esfuerzo rasante del forjado.

\subsubsection{Fachadas}

La composición del sistema de cerramientos está basada en una fábrica mixta de piedra caliza y ladrillo cerámico, con un revestimiento de mortero de cal y acabado en pintura, tanto en interior como en exterior. A lo largo de la historia, la Capilla ha tenido reparaciones poco afortunadas que han envejecido de manera incorrecta.

En las fachadas se apreciaba una degradación de color en el revestimiento y una fisuración en zonas puntuales, así como desconchados y ennegrecimiento parcial con presencia de líquenes junto a las cornisas. En definitiva, todos los elementos de la fachada, en general, 
han sufrido el paso del tiempo. Y tanto la polución ambiental como la falta de mantenimiento ha contribuido a su deterioro.

\section{Actuaciones de reparación}

\subsection{Actuaciones de restauración arquitectónica}

Debido al grado de protección existente sobre la Capilla, la intervención realizada mantuvo las condiciones estéticas y compositivas del edificio. La solución planteada para la reparación de las cubiertas de la nave principal y de la sacristía conservó las alineaciones exteriores, la altura y la geometría de los aleros y respetó los materiales originales vistos (teja) definiendo el mismo modelo y aprovechando, en la medida de lo posible, todo aquello que durante la demolición conservó su integridad. De este modo, se atienden las especificaciones de la Ley de Patrimonio Cultural de Asturias que permite solamente las actuaciones encaminadas a la conservación y mejora de sus condiciones de habitabilidad o uso.

Tal y como se ha expuesto anteriormente, la Capilla posee una elevada calidad en su conformación arquitectónica global, exterior e interior, siendo además muy representativa de un estilo de una época. Cabe destacar, especialmente, las soluciones constructivas adoptadas provistas de gran talento e ingenio. Sin duda el edificio posee valores ocultos bajo las distintas pieles edificatorias que le aportan valor dentro de la historia de la construcción.

\subsection{Intervención en la cubierta de la nave principal}

La reparación de la nave principal respondió a dos cometidos de gran importancia. Por un lado, la reparación y consolidación estructural y por otro lado la eliminación de las filtraciones de agua de lluvia.

En el primer cometido, el estructural, se decidió retirar las tejas existentes, la escoria de relleno, el tablero a dos aguas de doble rasilla y las correas metálicas. Todos ellos son elementos constructivos preexistentes. De este modo se descubrió la cara superior de la bóveda, exponiéndola a las inclemencias climatológicas durante parte del proceso constructivo de reparación de la cubierta. Se proyectó una intervención consistente en realizar una nueva estructura metálica que soportase las cargas del peso propio de la nueva cubierta y de las demás cargas de cálculo normativo. Los nudos inferiores de la celosía se apoyaron en los arcos fajones y estaban totalmente tapados por la bóveda de triple rasilla pasante. Por tanto, era desconocido su estado de conservación y esto llevó a descartar cualquier intervención consistente en picar la bóveda y en reforzar la celosía preexistente. Por este motivo, se proyectó una nueva doble celosía, una por cada lado de la preexistente, cuyo cordón inferior describía una circunferencia concéntrica a la bóveda, sin llegar a tocarla en ningún punto. Es decir, las nuevas celosías se apoyaron en dos puntos, en sus extremos, en los riñones de los arcos, donde se generaron unos apoyos de acero con un perfil HEA 200 embutido en mortero sin retracción. Así se conservaron y respetaron intactas las celosías originales y se transmiten cargas simétricas a los contrafuertes sin generar excentricidad. Además, se ejecutó un zuncho perimetral de hormigón armado de sección $30 \times 25$ centímetros a la altura de la coronación del muro de piedra (cornisa) para consolidar la fábrica en esta zona, "atar" los muros y dar apoyo lateral a las nuevas celosías y a las correas de las crujías extremas. Tras finalizar esta fase se distribuyeron nuevas correas metálicas IPE 160 biapoyadas con un refuerzo sobre el ala superior para ayudar a darles continuidad.

Una vez realizado el refuerzo estructural, se procedió a eliminar las filtraciones de agua de lluvia. Para ello se construyeron las diferentes capas de la cubierta, empezando por un aislamiento térmico de lana de roca, de 60 milímetros de espesor, con una cara con barrera de vapor, colocado sobre la bóveda. A continuación, se dispuso, apoyado en las correas, un tablero prefabricado tipo sándwich compuesto por dos capas exteriores de aglomerado hidrófugo y una interior de poliestireno extruido de 60 milímetros de espesor. Por encima de este se instaló una lámina impermeable transpirable y una lámina ondulada, también impermeable, para favorecer la ventilación de la cubierta. Finalmente se dispusieron las tejas árabes cerámicas, similares a las preexistentes, todas ellas sujetas con gancho de acero inoxidable para evitar desplazamientos y/o desprendimientos de estas. Se repararon los aleros respetando escrupulosamente su geometría original, tanto en 
la parte superior de las molduras como en la zona de hiladas de tejas superpuestas. Se estimó prudente reforzarlos estructuralmente considerando el peso de las tejas y la longitud de voladizo. Para ello se instalaron unas triangulaciones metálicas atornilladas a la cara exterior vertical del zuncho y la cara superior del alero. Estos perfiles quedaron ocultos bajo las tejas.

Durante la ejecución fue fundamental realizar trabajos con extrema precaución. A tal fin se instalaron cimbras bajo los arcos, se realizaron demoliciones paulatinas y cuidadosas, se limitó el tránsito sobre la bóveda y no se aplicaron cargas asimétricas ni sobre esta ni sobre los arcos que podrán descompensar su funcionamiento estructural.

\subsection{Intervención en la cubierta de sacristía}

La estructura metálica existente en la sacristía tenía un estado de conservación aceptable, por lo que no se planteó su sustitución. Se verificó que el empotramiento de los perfiles metálicos originales en la fábrica de mampostería era el adecuado y no requería intervención ni refuerzo alguno. En los laterales inferiores de la cubierta, en el apoyo horizontal sobre el muro de piedra, era necesario instalar unas vigas metálicas que descansarán en unos dados de mortero sin retracción con una placa de anclaje a la que soldar las nuevas vigas. Estos perfiles metálicos longitudinales, de encuentro con la fábrica de piedra, tienen sección en $\mathrm{T}$ a medida de $200 \mathrm{~mm}$ de altura y darán cabida y sustento a un zuncho superior de hormigón armado. Esto aportó solidez, cohesionó la fábrica y colaboró en asegurar la estanquidad en la unión de la cubierta con la mampostería.

Una vez realizada la consolidación estructural de la sacristía, se ejecutó la cubierta impermeable disponiendo las sucesivas capas que la conforman. Debido a la limitación existente que obligaba a conservar las alturas de cornisas y configuración de aleros, se propuso instalar un aislamiento reflexivo específico para cubiertas. Sobre este aislamiento se dispuso una lámina ondulada impermeable para aportar seguridad frente al agua y para ventilar interiormente la cubierta. Posteriormente se colocaron las tejas árabes con el mismo sistema que la nave principal. En este caso, todas las cobijas son aprovechadas de la cubierta preexistente. Finalmente se realizaron los remates de en- cuentros con paramentos verticales y se repararon los aleros respetando escrupulosamente su geometría original, tanto en la parte superior de las molduras como en la zona de hiladas de tejas superpuestas.

\subsection{Intervención en la torre del campanario}

Una vez analizadas las lesiones mecánicas existentes en la torre y las causas de las mismas (directas e indirectas), se realizó una intervención dirigida hacia la consolidación estructural basada principalmente en el refuerzo del sistema. Por un lado, se ejecutó un refuerzo del forjado del campanario debido a la falta de seguridad estructural que presentaba. Para ello, se colocaron unas vigas a modo de "parteluz" empotradas en los muros de piedra y se instaló una malla metálica reticular tipo tramex por la cara inferior del forjado cerámico.

El método de ejecución determinado para evitar riesgos fue instalar parteluces con doble perfil L 90.8, un perfil L 90.8 en todo el perímetro del forjado y una malla metálica de tramex T 40.3 de soporte en su cara inferior. De la misma manera, con el fin de reforzar el muro exterior del campanario, se proyectó un refuerzo para las pechinas con un perfil metálico HEB 140. La finalidad fue mantener el forjado cerámico, pero reforzando su seguridad estructural, limpiando los perfiles metálicos existentes con chorro de arena e imprimiendo una pintura especial anticorrosión.

Por otro lado, analizada la geometría de las grietas y fisuras en los muros, era necesario instalar un refuerzo estructural a modo de cinturón formado por una pletina de acero colocada por el exterior del campanario. Teniendo en cuenta el espesor del cerramiento y su esbeltez, se procedió a reforzar los muros de la torre con dos pletinas de acero 150.8, situadas en los puntos clave, actuando como cinturones que abrazan el edificio y contrarrestan los esfuerzos horizontales que está sufriendo la fábrica y que generan la aparición de grietas y fisuras. Los refuerzos se situaron en la base del pináculo y en la base de los huecos de fachada, donde están las grietas de mayor espesor, consolidando la parte alta de la torre.

El método de ejecución consistió en realizar el picado de la carga hasta el nivel de la piedra, colocando el refuerzo metálico (pletina 150.8) enrasado con el mortero de cal y pintado del mismo color que la fachada. 


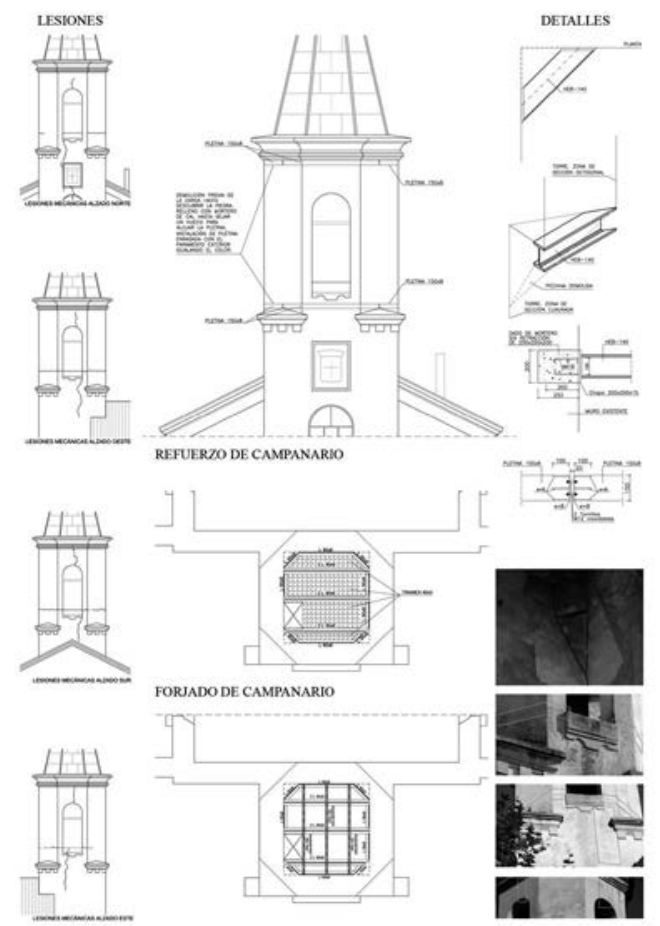

Fig. 6. Los autores del proyecto. Capilla de La Cadellada. Torre campanario. Análisis de grietas. Planos de la propuesta de reparación. Detalles constructivos de las estructuras. Fotografías de las lesiones. 2019.

Finalmente, en las grietas se inyectó mortero de cal hasta su colmatación y se remató la actuación restaurando el mortero de fachada y pintando. Analizando la sección obtenida y una vez realizado el refuerzo a estas dos alturas, se obtiene un equilibrio importante de puntos de atado de la torre.

\subsection{Intervención en las fachadas}

Teniendo en cuenta las características patrimoniales de la Capilla de La Cadellada, así como su grado de protección, y una vez analizadas las causas de las lesiones detectadas en las fachadas, se optó por realizar una actuación de restauración con materiales inorgánicos libres de "COVs", productos 100\% ecológicos con una base mineral.

En primer lugar, se realizaron trabajos previos a la intervención como fueron la protección de vidrieras, metal y carpinterías. También se comprobó la estanqueidad y la correcta evacuación del agua de la cubierta en todo el perímetro del alero.

Es imprescindible que los trabajos sean realizados sobre paramentos limpios, sanos y esta- bles. Por ello se realizó la limpieza de los muros de fachada por medios mecánicos y jabón neutro hasta la eliminación total de manchas, eflorescencias y verdines. También se procedió al rascado y eliminación de restos de revestimiento y pintura defectuosos, mal adheridos y craquelados.

Las reparaciones de los muros del sistema de fachadas fueron realizadas con morteros de cal natural tipo "Gordillos" para posteriormente aplicar sistemas de pinturas minerales con el fin de garantizar un resultado óptimo perdurable en el tiempo, utilizando materiales tradicionales y manteniendo la esencia en el proyecto de reparación.

Finalmente se aplicaron sistemas minerales específicos para exteriores basados en una aplicación de capa de acabado con pinturas de última generación con ligantes de sol de sílice y silicato potásico, previamente se aplicó una pintura de fondo armada con fibras a base de silicato con adición de acrilatos puros. Primera mano: aplicación de recubrimiento de fondo para igualar diferencias de textura y cubrir fisuras capilares finas. Se emplea como pintura-puente a fin de preparar los recubrimientos orgánicos firmes para la posterior aplicación de pinturas de dispersión de silicato. Rendimiento: $0,4 \mathrm{~kg} / \mathrm{m}^{2}$. Segunda mano: aplicación de pintura mineral de fachadas altamente especializada, basada en una combinación acreditada de ligantes de sol de sílice y silicato potásico, cumpliendo las exigencias de la norma DIN 18.363, 2.4.1 "pintura de dispersión de silicato". Rendimiento: $0,17-0,23 \mathrm{~kg} / \mathrm{m}^{2}$

Con este proceso de reparación se consiguió proteger la pintura antigua contra futuras degradaciones, reducir las condensaciones en la superficie y evitar la aparición de humedad. Dicho proceso ayudará a mantener los paramentos limpios gracias a que es un sistema antiestático y, por tanto, facilitará su repintado cuando tengan que ser renovados.

\section{Conclusiones}

Las intervenciones en el patrimonio tienen que estar muy estudiadas y documentadas. A través del análisis minucioso hecho se ha puesto de manifiesto que este edificio es un elemento arquitectónico de alto valor histórico-artístico, al tratarse de un sistema constructivo desapare- 
cido, que pertenece a la historia de la construcción y que hoy en día sería complejo reproducir.

Para conocer el estado patológico ha sido imprescindible determinar las causas (activas o pasivas) que actúan como origen del proceso y que desembocan en una o varias lesiones. De este modo, un proceso patológico no se resolverá hasta que no sea interrumpido en origen. Por el contrario, cuando únicamente se resuelve la lesión, sin atender a la causa, la lesión generalmente aparece de nuevo.

Las intervenciones deben ser soluciones arquitectónicas integradas y reversibles, con el fin de eliminar las causas de las lesiones físicas, químicas y mecánicas detectadas a través del análisis y del diagnóstico de las patologías del edificio, y siempre con la finalidad de conservar la naturaleza y la calidad de la edificación.

EQUIPO TÉCNICO EN LA REDACCIÓN DEL "PROYECTO BÁSICO Y DE EJECUCIÓN PARA LA REPARACIÓN DE LAS CUBIERTAS Y DE LA TORRE EN CAPILLA DE "LA CADELLADA" EN EL HUCA."

\begin{tabular}{ll}
\hline & $\begin{array}{l}\text { Miguel Crespo Vázquez. } \\
\text { Arquitecto }\end{array}$ \\
\cline { 2 - 2 } Autores: & $\begin{array}{l}\text { Daniel Simarro González. } \\
\text { Arquitecto }\end{array}$ \\
& Tamara García Fernández. \\
& Arquitecto Técnico \\
& $\begin{array}{l}\text { Javier Fuente Alonso. } \\
\text { PENTIA ESTRUCTURAS } \\
\text { S.L. Proyectista de } \\
\text { estructuras. }\end{array}$ \\
\hline
\end{tabular}

Francisco de Zuvillaga del Busto. Arquitecto

Estudio de S. y S: GRUPO PREVENORTE S.L.

INTERVINIENTES EN LA EJECUCIÓN DE LA OBRA:

\begin{tabular}{ll}
\hline & $\begin{array}{l}\text { Miguel Crespo Vázquez } \\
\text { (arquitecto) }\end{array}$ \\
\cline { 2 - 2 } $\begin{array}{l}\text { Dirección de } \\
\text { Obra: }\end{array}$ & $\begin{array}{l}\text { Daniel Simarro González } \\
\text { (arquitecto) }\end{array}$ \\
\hline
\end{tabular}

Dirección de Ejecución de Tamara García Fernández. Obra: Arquitecto Técnico

Coordinación de S. y S:

GRUPO PREVENORTE S.L.

Empresa constructora:

PERALTE S.A.

\begin{tabular}{ll}
\hline & $\begin{array}{l}\text { PROCOMESA (estructura } \\
\text { metálica) }\end{array}$ \\
\cline { 2 - 2 } $\begin{array}{l}\text { Subcontratas } \\
\text { principales: }\end{array}$ & $\begin{array}{l}\text { LA CASA POR EL TEJADO } \\
\text { (cubiertas) }\end{array}$ \\
\cline { 2 - 2 } & $\begin{array}{l}\text { KEIM - TENYSOL (pintura } \\
\text { exterior) }\end{array}$ \\
\hline & $\begin{array}{l}\text { GISPASA S.A.U. (Gestión de } \\
\text { Infraestructuras Sanitarias } \\
\text { del Principado de Asturias) } \\
\text { perteneciente a la Conse- } \\
\text { jería de Hacienda y Sector } \\
\text { TOROMO- }\end{array}$ \\
OBRAS: & \begin{tabular}{l} 
Público. \\
\hline
\end{tabular} \\
\hline
\end{tabular}

\section{Referencias bibliográficas}

FONDOS DE LA DIPUTACIÓN PROVINCIAL. "Expediente de contratación de la ejecución de obras de mejora en la Capilla del Hospital Psiquiátrico Provincial". caja 0479/30, Exp. 10344. 1961.

FONDOS DE LA DIPUTACIÓN PROVINCIAL. "Expediente de contratación del servicio de pintura de un mural que representa la Sagrada Cena en la Capilla del Hospital Psiquiátrico Provincial, adjudicado a Paulino Vicente Rodríguez". Caja 0480/11, Exp. 10357. 1961.

FONDOS DE LA DIPUTACIÓN PROVINCIAL. "Expediente de adquisición de tres vidrieras artísticas con destino a la Capilla del Hospital Psiquiátrico Provincial". Caja 0480/16, Exp. 10362. 1961.

FONDOS DE LA DIPUTACIÓN PROVINCIAL. "Expediente de contratación del montaje de un andamio para la pintura mural de la Capilla del Hospital Psiquiátrico Provincial que ejecutará Paulino Vicente Rodríguez". Caja 0480/21, Exp. 10367. 1962.

FONDOS DE LA DIPUTACIÓN PROVINCIAL. "Contratación de proyecto de reparación de la cubierta de la Iglesia del Hospital Psiquiátrico". Caja 69196/07, Exp. 10344. 1986. 
TEJO PÉREZ, José Ramón. Las campanas de Oviedo. Oviedo: Ciudad Cultural. № X. 1988.

SECADES FERNÁNDEZ, Patricia. "El estilo Internacional en el Hospital Psiquiátrico de la Cadellada”. Liño 13. Revista anual de Historia del Arte. Universidad de Oviedo. 2007

SECADES FERNÁNDEZ, Patricia. "Los conjuntos arquitectónicos y su importante valor patrimonial. La parcela de la Cadellada." Liño 15. Revista anual de Historia del Arte. Universidad de Oviedo. 2009.

CRESPO VÁZQUEZ, Miguel; PANDO ÁLVAREZ, Sara; ROCES RODILLA, Ana; SIMARRO GONZÁLEZ, Daniel; DE ZUVILLAGA DEL BUSTO, Francisco. "Análisis Constructivo de la Capilla de la Cadellada (1926-1944). Oviedo". Revista electrónica ReCoPaR POLITÉCNICA. № 10. 2013. http://polired.upm.es/index.php/recopar/article/download/2231/2313

MONJO CARRIÓ, Juan. Tratado de Rehabilitación, Tomo 1, Teoría e historia de la rehabilitación. Editorial Munilla-Leria. DCTA - Universidad Politécnica de Madrid. Madrid. 1999.
MONJO CARRIÓ, Juan. Tratado de Rehabilitación, Tomo 2, Metodología de la restauración $y$ de la rehabilitación. Editorial Munilla-Leria. DCTA - Universidad Politécnica de Madrid. Madrid. 1999.

MONJO CARRIÓ, Juan. Tratado de Rehabilitación, Tomo 3, Patología y técnicas de intervención. Elementos estructurales. Editorial Munilla-Leria. DCTA - Universidad Politécnica de Madrid. 2008.

MONJO CARRIÓ, Juan. Tratado de Rehabilitación, Tomo 4, Patología y técnicas de intervención. Fachadas y cubiertas. Editorial Munilla-Leria. DCTA - Universidad Politécnica de Madrid. 1999.

FERNÁNDEZ LÓPEZ, María Amparo. Tradición y renovación en la pintura de Paulino Vicente 1900-1990. Editorial Trymar. Vigo. 2000.

GÓMEZ LÓPEZ, Benigno; GONZÁLEZ BLANCO, Miriam. Estudio documental del Complejo del Hospital Psiquiátrico de la Cadellada. Oviedo. Consejería de Educación y Cultura. 2002

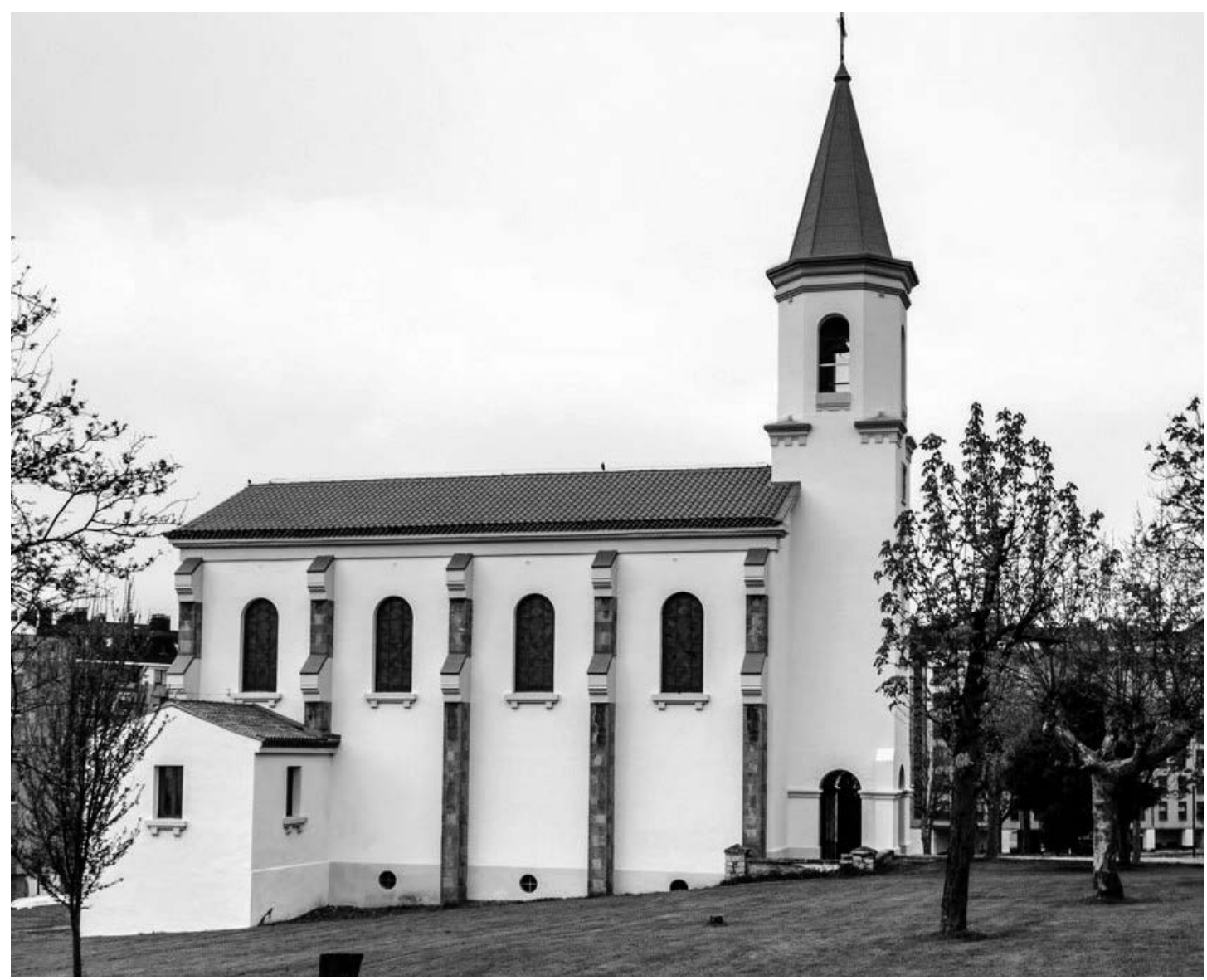

Fig. 7. Arquitecto: Manuel Bobes. Capilla de La Cadellada. Hospital Universitario Central de Asturias. Oviedo. Finalización: 1944. Foto tomada por los autores del artículo en 2020. Estado actual tras la intervención. 